\title{
Parasitic Contamination of Vegetables in Jos, Nigeria
}

\author{
J. G. Damen, E. B. Banwat, D. Z. Egah And J. A. Allanana \\ Department of Medical Microbiology, Jos University Teaching Hospital, Jos, Nigeria \\ Reprint requests to: J. G. Damen, Medical Microbiology Department, Jos University Teaching Hospital, \\ P. M. B. 2076, Jos, Plateau State, Nigeria.E-mail:_damenjgd@yahoo.com
}

\begin{abstract}
Background: Intestinal parasites are very common in developing countries including Nigeria. There are diverse ways of their transmission; the study attempts to determine the level of intestinal parasitic contamination on vegetables sold in Jos.

Methods: Sample of 200 each of Tomatoes (Lycopersium sativus), Letus (Loctus satival) Carrot (Davcus carota L) Cabbage (Brassica Denceal) and Green leafy vegetables were analyzed using standardized Centrifugal-floatation technique methods.

Results: Of the 1250 samples of vegetables examined, 450 (36.0\%) were positive for intestinal parasites, cabbage recorded the highest prevalence of $64 \%$ while tomatoes had the least prevalence of $20 \%$.

Conclusion: Vegetables in Jos are heavily contaminated with intestinal parasites and there is need for public enlightenment campaign on the danger of consuming inadequately washed and prepared vegetables.
\end{abstract}

Key words: Intestinal parasite, vegetable, contamination

\begin{abstract}
Résumé
Contexte: Les parasites intestinaux sont très communs dans les pays en voie de développement y compris le Nigéria. Il y a différents moyens de transmission; le but de cette étude est de déterminer le niveau de contamination intestinale des parasites à partir des légumes vendus à Jos.

Méthode: 200 échantillons de chaque légume à savoir: les tomates (lycopersium saticus), la laitue (Loctus satival), les carrottes (Davcus carota L), les choux (Brassica Denceal) et les légumes verts furent analysés grâce à l'utilisation des méthodes standardisées Centrifugal-floatation.

Résultats : Des 1250 échantillons de légumes examinés, 450 (36\%) étaient positifs en parasites intestinaux, la choux a révélé la fréquence la plus haute avec $64 \%$ contamination tandis que la tomate a révélée la fréquence la plus faible avec $20 \%$ de contamination.

Conclusion: Les légumes à Jos sont hautement contaminées par des parasites intestinaux et il y a besoin de sensibiliser le public sur le danger de leur consommation dans le cas ou ces légumes ne sont pas bien lavés ou bien cuits.
\end{abstract}

Mots-clés : Les parasites intestinaux, Les legumes, de contamination

\section{Introduction}

Vegetables in its broadest sense, refers to any kind of plant life or plant products. It is also commonly referred to as the fresh edible portion of a herbaceous plants roots, stems, leaves or fruits. These plants are either eaten fresh or prepared in a number of ways. ${ }^{1}$

The climate, vegetation and topography of Plateau State are suitable for the cultivation of these vegetables. They are grown throughout the year in Plateau State, using rain during wet season and irrigation during dry season. Irrigation water is derived from two sources, rivers and mine ponds. These two sources are usually highly polluted with human and animal faeces. ${ }^{2}$ It is a known fact that the use of excreta polluted irrigation water is a health risk to the farmer and consumers of crops so produced. Raw wastewater frequently contains high numbers of eggs of human intestinal nematodes. ${ }^{3}$ The increasing use of wastewater for irrigation in the 1970s and early 1980 s prompted a series of literature reviews and investigation into the global extent of waste water reuse and its associated human health risk. The infection can also be a household affair where infected children or persons provide the chief source of soil contamination by their promiscuous defecation in the soils. ${ }^{4}$ Market vegetables are often contaminated by eggs of human intestinal nematodes 
where night soil is extensively used as fertilizer or wastewater reuse is practiced. Both crop consumers and the agricultural worker have been identified as being at high risk from soil and wastewater transmitted infection.

The direct application of night soil, animal manure and wastewater as an agricultural fertilizer has been practiced for centuries in many parts of the world, particularly in the Asian sub-continent. ${ }^{5}$ The practice is gaining prominence, in developing countries as a result of the growing cost of mineral fertilizers and because of the increasing demand for basic food supplies. Indirect reserve of river water which contains a substantial

percentage of municipal referee and sewage is also going on many developing countries. ${ }^{6}$

Epidemiological studies have indicated that in areas of the world where helminthic diseases are endemic in the population and where raw untreated waste water is used to irrigate vegetables generally eaten uncooked, the consumption of such waste irrigated vegetables may lead to parasitic infestation. ${ }^{7}$

This work was designed to detect the human intestinal parasites that infect man through eating of raw and improperly washed vegetables and the ways in which they could be controlled.

\section{Materials and Methods}

\section{Study area}

This study was carried out in Jos metropolis during the dry season (October 2002 to February 2003). This was because; the irrigation farmers make substantial investments towards the building of canals and appurtenances through which the water bodies flow. The water bodies that flow into these canals receive numerous discharges of raw sewage; night soil and municipal/community refuse from the municipality with some diversions from where the waste waterladen river was transported to cultivation areas through irrigation canals.

\section{Areas of sampling}

These vegetables were picked from six areas (terminus main market, Kwararafa market, Gada Biu market, Farin Gada tomatoes market, building material vegetable market, and Angwa Soya garden) all in Jos metropolis, Plateau State. These markets were considered because majority of the farmers from different local government areas of Plateau State convey their farm products, which include the abovementioned vegetables for sale in these markets. Also the garden at Angwa Soya was considered because the flowing water bodies surrounding it receive contaminations of raw sewage, waste refuse and polluted water from the community.

\section{Collection of samples for the study}

The vegetables used in this study were tomatoes (Lycopersicum Sativus L), lettuce (Lactus Sativa L), carrots (Daucus Carota L), cabbage (Brassica Deracea $L$ ) and green leafy vegetables. Two hundred each of tomatoes letus, carrot, cabbage, and green leafy vegetables were picked randomly from the above markets to obtained qualitative estimation of parasitic contamination of these vegetables.

\section{Processing of the sample}

Macroscopic examination

Each of the samples was examined carefully for the presence of segment of cestodes and adult nematodes.

Procedure for washing the samples

The vegetables were washed for the removal or elutions of the parasitic ova, larva or cysts. This was done using the washing method described by Gaspard and Schwartzbrod. ${ }^{8}$ In this method, the experimental protocol consisted of the elution of eggs from the vegetable substrate and concentration. Elution of the eggs was achieved by brushing the vegetables with the cationic detergent, Hyamine solution (Hyamin 1622 Fass Co) containing glass powder suspension in water 50/50 (100-200mm borosilicate pyrex particles) and rinsing with water. Concentration of the eggs was done by centrifugal-floatation technique described by Stein and Schwartz. ${ }^{9}$ The preparation was filtered through wet gauze into a clean one liter conical flask to remove debris and then dispensed into clean centrifuge tubes and centrifuged at $5000 \mathrm{rpm}$ for 5 minutes, the supernatant was discarded into disinfectant jar and the sediment was mixed and a drop was applied on the center of a clean grease-free slide, a clean cover slip was placed gently to avoid air bubbles and over flooding. The preparation was examined under the microscope for parasites using $\mathrm{x} 10$ and $\mathrm{x} 40$ objectives.

\section{Results}

A total of 5 different types of vegetables (250 of each vegetable type) were examined for parasitic contamination. Cabbage had the highest contamination rate of $160(64 \%)$, lettuce $100(40 \%)$, carrot $80(32 \%)$, green leafy vegetable $60(24.0 \%)$ and tomatoes $50(20.0 \%)$. The overall parasitic contamination of the vegetables was 450/1250 (36\%).

The rate of parasitic contamination of vegetables examined in different markets were Gada Biu market $150(60 \%)$, building materials vegetable market 100 (40\%), Angwan Soya garden 63 (36.0\%), Kwararafa market $60(24.0 \%)$, Farin Gada tomatoes market 50 $(20 \%)$ and Terminus main market 40 (16.9\%). Trichomonas hominis had the highest contamination prevalence of 112 (24.9\%), Hookworms 89 (19.8\%), Ascaris lumbricoides 77 (17.1\%), Strongyloides stercoralis 75 (16.7\%), Entamoeba histolytica 63 (14.0\%), Trichuris trichiura $23 \quad(5.1 \%)$ and Hymenolepis nana 11 (2.4\%). 


\section{Discussion}

The findings from this study have shown that parasitic eggs, larvae and cysts can be found at harvest on vegetables grown with human and animals waste and/or by irrigation. Of the 1250 samples of vegetables that were collected processed and examined 450 of them were contaminated with parasites. We found out that cabbage had the highest parasitic contamination (64\%) and tomatoes $20 \%$ recorded the least parasitic contamination, this could be due to the fact that the degree of contamination varies according to the vegetables. Cabbage, lettuce and green leafy vegetables had uneven surfaces and makes parasitic eggs, larva attached to the surface of the vegetable more easily, either in the farm or when washed with contaminated water, while tomatoes had the least prevalence because of its smooth surface which reduces the rate of parasitic attachment.

Gada Biu market recorded a higher prevalence of $60 \%$ in all the market studied followed by building materials vegetable market $40 \%$ Kwararafa market 24.0\% while Angwan Soya Garden and Farin Gada tomatoes market $20 \%$ each and Terminus Main Market recorded the least prevalence of $16.0 \%$. The highest prevalence of contamination with parasites was found in the vegetables sold in the mini markets could be attributed to the water used in washing the vegetables. There are ponds and wells near these markets and the women selling these vegetables use the water. The terminus main market recorded the least parasitic contamination; this might be due to the fact that the water used in washing the vegetables was pipe born which has minimal parasitic contamination.

It was remarkable to note that among the seven different intestinal parasites identified in the study, Trichomonas hominis a flagellate that does not have a cystic form to withstand adverse environmental condition recorded the highest prevalence of $24.9 \%$. The water used in washing the vegetable might introduce this parasite. This was followed by soil transmissible helmniths; they are indicators of poor socio-economic condition, as well as poor environmental and sanitation practices. The presence of protozoa and cestodes might be due to lack of modern toilet facilities, inadequate public health enlightenment and illiteracy that makes people defecate indiscriminately resulting in pollution of water and farmland.

The finding of this study is similar to previous reports, 10, 11 which had indicated parasitic contamination of locally consumed vegetables. It has also been reported ${ }^{6,12}$ that due to the persistence and ability to withstand a wide variety of adverse environmental condition by helminthes, they could serve as indicators of water pollution.

Our results showed that locally consumed vegetables are often contaminated with human intestinal parasites where night soil or wastewater reuse is practiced. Crop consumers and agricultural workers alike, are at high risk of parasitic infections in Jos. This is because irrigation water being used in Jos metropolis does not meet the WHO standard and is therefore unsafe for use in the production of carrots, cabbage, lettuces, tomatoes and green leafy vegetables. One report ${ }^{13}$ observed that there is evidence that people consuming vegetables irrigated with raw wastewater are exposed to the risk of infection with ascaris, trichuris, amoeba and tape worm.

We conclude that irrigation farming in Jos metropolis leads to parasitological pollution of vegetables especially with viable and infective stage of protozoa, nematodes and cestodes. Control measures will therefore include treatment of irrigation water, municipal wastewater, before use; treatment of infected persons, mass education of the populace on the inherent dangers in eating inadequately washed vegetables. Provision of good sanitary system in the rural and urban areas to prevent contamination of soil and water with parasites from poor deposition of faeces should be adopted as the control measure of parasitic contamination of vegetable.

\section{Acknowledgement}

The author appreciates the assistance of the technical staff of Parasitology laboratory of Jos University Teaching Hospital for their co-operation during this study.

\section{References}

1. Encyclopedia Britannica. Encyclopedia Britannica Inc, Chicago, 1969, Volume 23

2. Okorokwo MO. Intestinal Parasites associated with human and animal waste stabilization in Jos and Barkin Ladi areas of Plateau State, Nigeria. PhD Thesis, University of Jos, Jos 1998

3. Ayer RM, Scott R, Lee DD, Silve SA. Contamination of lettuce with nematode eggs by spray irrigation with treated and untreated wastewater. Water Science and Technology 1992; 26: 1615-1623

4. Brown HW, Neva FA. Basic clinical parasitology. Appleton-Century-Crofts, Norwalk, 1983

5. Shuval HI, Adon A, Fattai B, Rawitz E, Yukiel P. Waste water irrigation in developing countries; health effects and technical solution. World Bank, Technical Paper 1986;51

6. World Health Organization health guidelines for the use of waste water in agriculture and agriculture. WHO, Geneva, Technical Report Series No. 1989778

7. Mara D, Cairu CS. Guidelines for the safe use of wastewater, and excreta in agriculture and agriculture measures for public health protection. Measures for public health protection. WHO, Geneva, 1989; 21-187

8. Gaspard P, Schwartzbrod J. Determination of the parasitic contamination of irrigated vegetables. Environmental Quality and Ecosystem Stability 1991; 289-296 
9. Stein JL, Schwartz BJ. Technique des concentration venefs d' helminthes; valcurs et limiters; proceedings collguefes; egux continentals resources of assainssement 1986; 48

10. Mba OO. Detection and enumeration of parasite eggs in irrigated vegetable and salad crops in Plateau State, Nigeria. J Med Lab Sci 2000; 9:3036

11. Khali L. The Paul closet as an efficient means of controlling human helminthes infection as observed in Tura prison, Egypt with a discussion on sources of ascaris infection. Ann Trop Med
Parasitol 1931; 25: 35-62

12. Kagie N. Techniques for the measurement of environmental pollution by infective stage of soil-transmitted helminthes. Collected Papers on the Control of Transmitted Helminthes 1982: 11; $27-46$

13. Shuval HI, Yekutiel P, Fattai B. Epidemiological evidence for helminthes and cholera transmission by vegetables irrigated with wastewater; Jerusalem, a case study. Water Science and Technology 1984; 17: 433-442 